\title{
Águas urbanas: três projetos para São Paulo
}

\author{
Anne Marie Sumner*
}

Resumo Os projetos debruçam-se sobre as hipóteses da Arquitetura na sua interface com a infraestrutura para águas urbanas em São Paulo, tendo como vetor principal a articulação de uma ação ética, técnica e estética. Procurase pensar a paisagem e arquitetura das águas urbanas em dupla instância: a montante com barragens e piscinas públicas e à jusante com deltas, lagoas e canal de circunvalação ladeando o Tietê. Faz parte deste último escopo a abordagem, também ao longo dos trilhos das antigas Sorocabana, Central do Brasil e Santos-Jundiaí. A inquietação é a de desenhar a geografia e a infraestrutura numa apreensão ótica da paisagem: um desdobramento visual, táctil e vivencial da cidade como opacidade (ou transparência) e situação (ou indefinição do lugar).

Palavras-chave: águas urbanas, arquitetura, infraestrutura.

\section{Aguas urbanas: tres proyectos para São Paulo}

Resumen Los proyectos abordan las hipótesis de la arquitectura en su interfaz con la infraestructura para aguas urbanas en São Paulo, teniendo como vector la articulación de una acción ética, técnica y estética. Buscamos pensar tal enfoque en dos casos: aguas arriba con un sistema de presas y piscinas públicas y aguas abajo con deltas, lagunas y canal de circunvalación que bordean el Tietê. Parte de este alcance es el enfoque a lo largo de los rieles de los antiguos ferrocarriles Sorocabana, Central do Brasil y Santos-Jundiaí. La preocupación es dibujar la geografía y la infraestructura en una comprensión óptica del paisaje: una percepción visual, táctil y experimental de la ciudad como opacidad (o transparencia) y situación (o falta de definición).

Palabras clave: aguas urbanas, arquitectura, infraestrutura.

\section{Urban waters: three projects for São Paulo}

Abstract The text and projects consider Architecture hypotheses in their interface with infrastructure for Urban Water in São Paulo, driven mainly by articulating ethical, technical and aesthetic initiatives. The landscape and architecture of urban waters are thought of in two instances: upstream in a system of small dams, with public swimming pools and downstream with deltas, lagoons and bypass channel along the foothills of the Serra da Cantareira as bordering the Tietê. The latter scope also includes the approach adopted along the rails of the old Sorocabana, Central do Brasil and Santos-Jundiaí railways. The concern is to draw the geography and infrastructure from a landscape perspective: a visual, tactile and existencial view of the city such as its opacity (or transparency) and location (or undefined location).

Keywords: urban waters, architecture, infrastructure. 


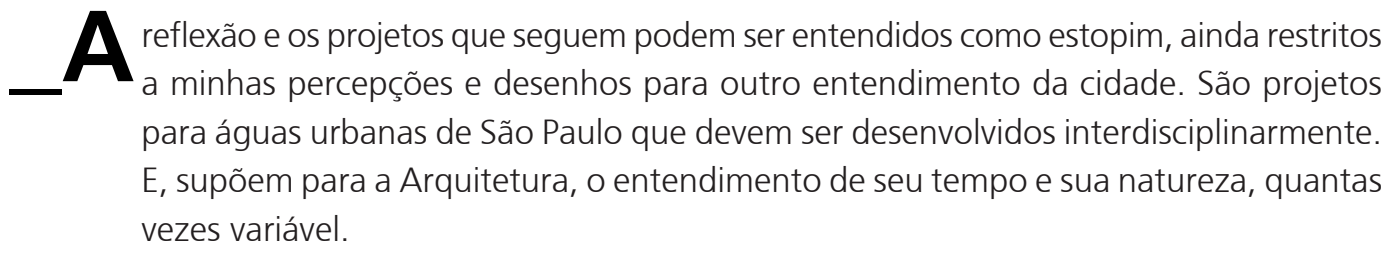

A informaçãa, potente ferramenta e substrato da situação contemporânea, contém, entretanto, uma espécie de correlato contrário que é o da constante remissão sígnica: um mundo imagético da referência em cadeia em que tudo refere a um outro, nada é realmente, tudo se equivale. E se a obra combina, não reflete, apenas associa segundo um código qualquer. Difícil conceber a arquitetura, porque nesta variabilidade ela pode ser qualquer uma, o que não significa que ela não se dê. Embora o raciocínio sistêmico não seja mais possível e tampouco a variabilidade parece constituir uma hipótese, minha atenção e energia tendem a estar mais próximas às questões de infraestrutura.

A cidade como possibilidade plena dos cidadãos existe fundada em uma relação entre civilização e cultura, onde a primeira realiza e concretiza a invenção e hipótese da outra. O que temos visto, contudo, é que a razão instrumental, em princípio civilizatória, ao passar a ter em si própria o seu sentido - e agir, portanto, independente da cultura - fica sem sentido. A defasagem monumental entre rede de infraestrutura e malha urbana em muitas cidades e metrópoles brasileiras dá a medida da redução do nosso contrato social como sociedade civil. Exemplos de tal defasagem associada à leniência urbana ${ }^{1}$ são o Minhocão, os alagamentos com os quais convivemos a cada verão, as escolas de lata, os terminais em praça pública: Bandeira, D. Pedro II e Princesa Isabel. Por que haveríamos de estacionar - nas áreas centrais e em praça pública - dupla contradição, aquilo que por natureza circula, o ônibus? Por leniência e/ou inércia de uma engenharia de tráfego que foi prática mundial, puramente instrumental que ainda se perpetua entre nós? Esta é uma indagação que poderá ser aprofundada pelos colegas da Filosofia, História e Ciências Sociais.

A metrópole é a manifestação exacerbada da cidade contemporânea com todas as deformações correlatas a esta exacerbação de escala. É também, das condições urbanas contemporâneas, a mais complexa e do ponto de vista da produção de conhecimento, seguramente a mais instigante.

* Anne Marie Sumner é Arquiteta e Urbanista, professora da Faculdade de Arquitetura e Urbanismo da Universidade Presbiteriana Mackenzie, ORCID <https://orcid.org/0000-0002-31603790>

1 SUMNER, Anne Marie. Leniência Urbana. Revista Móbile, n. 3, p. 21-22. Jul-Ago. /2016.
Pensar a relação arquitetura e metrópole é proporcionar a sua funcionalidade infra estrutural, mas é também apreendê-la: seus traçados, sua geografia.

Nos três projetos apresentados a seguir, as lagoas revividas nos portos de areia junto com o canal paisagístico e de retenção ao longo dos trilhos; o canal de circunvalação, paralelo ao rio Tietê, as piscinas públicas à montante no córrego do Guaraú desaguando no Cabuçú de Baixo, fazem parte da inquietação de desenhar a geografia e infraestrutura numa apreensão ótica da paisagem: um desdobramento visual, táctil e vivencial da 
2 O termo apreensão ótica foi usado na tese de doutorado de Anne Marie Sumner e proposto em interlocução com Otília Beatriz Fiori Arantes. Ele aparece no Preâmbulo, referindo aos projetos apresentados na tese e faz parte ainda da linhagem dos autores da pura visibilidade, que observam as diferenças entre uma natureza ótica e táctil da arte. (SUMNER, 2002, p.8).

\begin{abstract}
3 Em um mundo de imagética incessante, apreender a paisagem ou o entorno tornou-se uma dificuldade: como deter o olho que não para de passar? Na II Bienal Internacional de Arquitetura de São Paulo, em 1992, foi apresentado o projeto Opacidade e Situação, que trazia a inquietação sobre esta invisibilidade na metrópole contemporânea. O projeto publicado na Revista Oculum n.4, p. 38, nov. 1993, trazia o seguinte texto: "Não há oposição à paisagem seja ela construída ou natural. Tampouco uma vontade de Integração a ela. Nem tão simplesmente um evidenciar da paisagem. Trata-se de um campo comum onde um supõe o outro. Deserto, muro, telas e lâminas detém o olho que não para de passar".
\end{abstract}

4 Projeto apresentado para o Chamamento Arco Tietê, n 1/2013/ SMDU. Consórcio Candido Malta Campos e Centro Tecnológico de Hidráulica da Universidade de São Paulo e Autora do presente artigo como Arquiteta Convidada. Colaboradores Arquitetos. Andrea Conard, Juliana Pellegrini, Uriel Bianchini Cardoso. Os Engenheiros ligados ao FCTH-USP são: Luiz Orsini, Orlando Natale, Ana Paula Brites. cidade como opacidade (ou transparência) e situação (ou indefinição do lugar). Delineia a vontade, mesmo em se tratando de infra estruturas, de estabelecer situações de referência perceptiva; de criar diferenças em uma cidade saturada, sem com isso criar focos fixos de atenção, o "monumento" ou mesmo o edifício isolado, um partido que envolve tornar visível as malhas e seus interstícios, sua geografia e topografia, permitindo sua "descongestão": o fluir das pessoas e informações, o desbloqueio tanto da visão quanto dos sistemas de fluxos e águas. ${ }^{2}$

Se a escala e extensão da infraestrutura de uma cidade dão a medida (ou o limite) do contrato social daquela sociedade, quanto mais ampla e acessível a infraestrutura de uma cidade, mais completo o contrato social daquela sociedade. E, claro, em sentido pleno, Vida Ativa no dizer de Hannah Arendt.

Mas a visão de cada obra faz parte da hipótese intrínseca a ela. E não apenas na ação da arquitetura, mas no exercício da sociedade civil - o que possibilita a obra no seu melhor - a articulação entre ética, técnica e estética.

Apreender a cidade é apreender onde estamos. No alto, baixo, vale, planície, norte, sul, rio, entre rios, colinas, rarefação, adensamento, periferia, centro. A arquitetura se estrutura sempre em situação, mesmo que abstraia o entorno. É ela que torna visível e táctil a paisagem, construída ou natural. Trata-se de uma visão. O partido do ponto de vista espacial, em sentido amplo, é o de tornar esta cidade - tão saturada e ao mesmo tempo tão esgarçada - visível na sua estrutura e geografia: como deter o olho que não para de passar? ${ }^{3}$

O artista não fala a obra, mostra. Para o arquiteto, sua melhor fala é mostrar e eventualmente pontuar os projetos.

\section{Projetos}

\section{Projeto 1 - Arco Tietê Consórcio Candido Malta Campos - Fundação Centro Tecnológico de Hidráulica da USP + Arquiteta convidada: a autora. Junho, 20134}

O chamamento público para o Arco Tietê, teve como abrangência a área ao norte do rio Tietê desde o Tatuapé até seu encontro com o rio Pinheiros. Tendo participado como arquiteta convidada, voltada especificamente para projetos de águas urbanas envolvendo novas morfologias, a primeira abordagem foi a partir do levantamento do leito maior do rio Tietê (a área máxima da várzea) produzido por meio de aerofotogrametria em 1930 realizada pela empresa Sara Brasil. (Figura 1)

O mapa Sara do leito maior, sobreposto à situação cadastral e urbana atual com a retificação do Tietê indicam juntos, a área de escoamento e drenagem original - e perene - do rio. Mesmo com outra configuração espacial, estas áreas constituem o leito maior do rio Tietê - a área máxima de sua várzea - e são, portanto, fundantes. O contrário é a atual condição afogada do paulistano a todo verão.

Na grande inundação de 1929, a Pinacoteca do Estado fazia parte do leito maior, isto é, o nível e área máximos que a água atinge aproximadamente a cada 100 anos. 


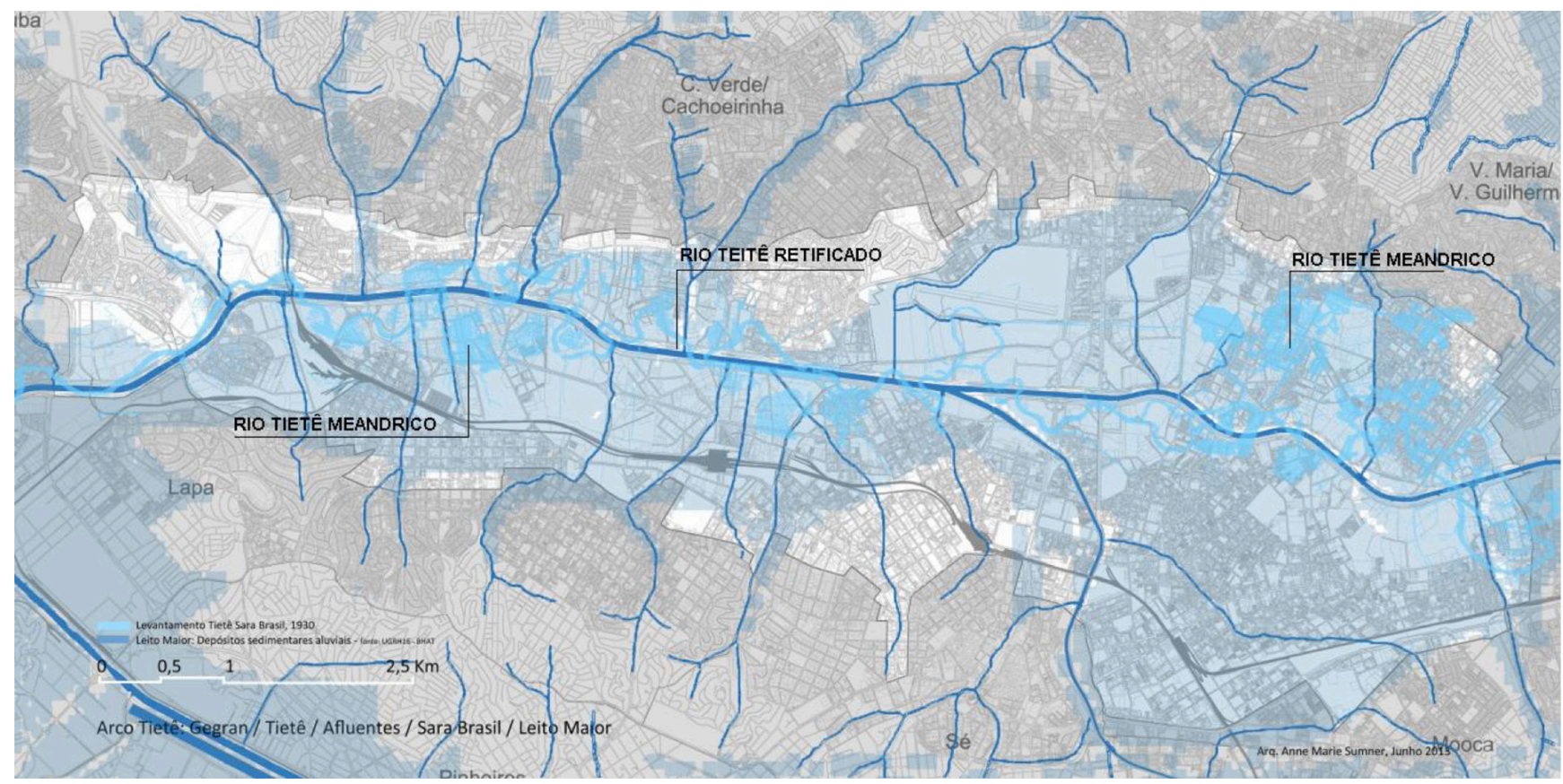

Figura 1: Em azul a área máxima de inundação da várzea do rio Tietê (nominada leito maior) e afluentes sobreposto ao mapa cadastral de São Paulo em branco e cinza. Levantamento apresentado para o Chamamento Arco Tietê, n 1/2013 SMDU. Fonte: Elaborado com base no Acervo Técnico do Gegran (Grupo Executivo da Grande São Paulo): Sobreposição do Mapa Hidrográfico de São Paulo, Tietê/ Afluentes e Sara Brasil 1930: Leito Maior, 2013.
O rio sempre voltará a procurar sua área original, da forma que tiver que fazê-lo. A ideia é re-desenhá-lo e fazer vê-lo.

O substrato para as proposições do Canal de Circunvalação, Deltas e Canais locais (Figuras 2, 3 e 4) é a caracterização de uma nova morfologia que articula a várzea plana com o sopé da serra da Cantareira, envolvendo a infraestrutura das águas e paisagem urbanas.

\section{Canal de circunvalação}

Como proposta inicial, o canal de circunvalação é um canal largo e aberto na cota 730m, que se estende do rio Tietê meândrico, lindeiro à entrada de São Paulo a leste pela rodovia Ayrton Senna, até o encontro com o rio Pinheiros a oeste. Trata-se de diretriz conceitual, articulando desenho urbano e infraestrutura com o intuito de fazer cidade no seu melhor. Na escala do pedestre estrutura-se um parque fluvial bordejante, dos primeiros indícios do sopé da Cantareira. A ideia é receber águas das bacias dos afluentes do Tietê antes de sua foz, a fim de aliviá-lo. Os córregos Cabuçú de Baixo, Mandaqui e Carandirú, entre todos os demais, são retidos no canal de circunvalação e escoados lentamente após as chuvas até o Tietê. Naturalmente, procedimentos técnicos como barragens móveis, caixas de areia e filtragem deverão ser dimensionadas caso a caso, considerando vazões, cargas difusas e sedimentos. Além disso, as propostas seguintes - os deltas e canais transversais locais - são também retenções para que essas águas cheguem aos seus rios mais lentas e limpas. 


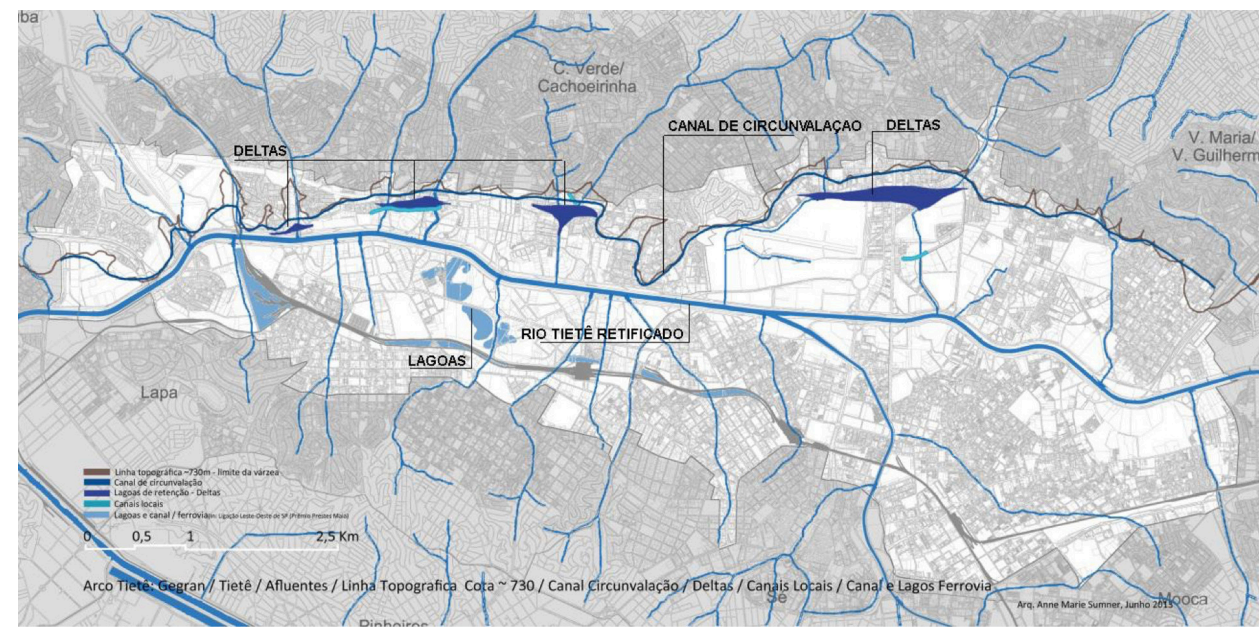

Figura 2 (em cima): Projeto Conceitual com Canal de Circunvalação, Deltas, Canais Locais, Canal e Lagos Ferrovia, sobreposto ao mapa cadastral de São Paulo em branco e cinza. O limite do canal de circunvalação coincide com a Linha Topográfica no sopé da Serra da Cantareira na cota aproximada $730 \mathrm{~m}$. Fonte: Elaborado com base no Acervo Técnico do Gegran (Grupo Executivo da Grande São Paulo) e Sobreposição do Mapa Hidrográfico de São Paulo, Tietê/ Afluentes e Sara Brasil 1930: Leito Maior (em branco), 2013.

Figura 3 (meio): Perspectiva do Projeto Conceitual com relevo e Canal de Circunvalação, Deltas, Canais Locais, Canal e Lagos Ferrovia. Fonte: Elaborado com base no Acervo Técnico do Gegran (Grupo Executivo da Grande São Paulo) e Sobreposição do Mapa Hidrográfico de São Paulo, Tietê/ Afluentes e Sara Brasil 1930: Leito Maior (linha de contorno

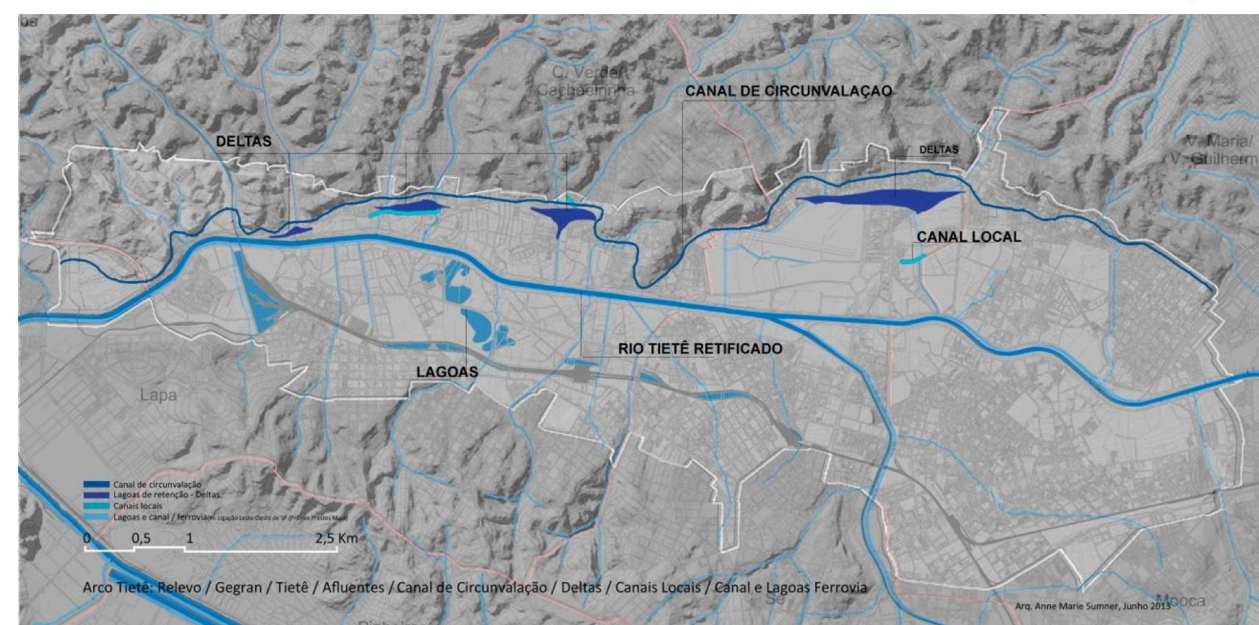
em branco), 2013.

Figura 4 (embaixo): Perspectiva aérea do Projeto Conceitual com Canal de Circunvalação, Deltas, Canais Locais, Canal e Lagos Ferrovia. Fonte: Elaborado a partir de Google Earth, 2013.

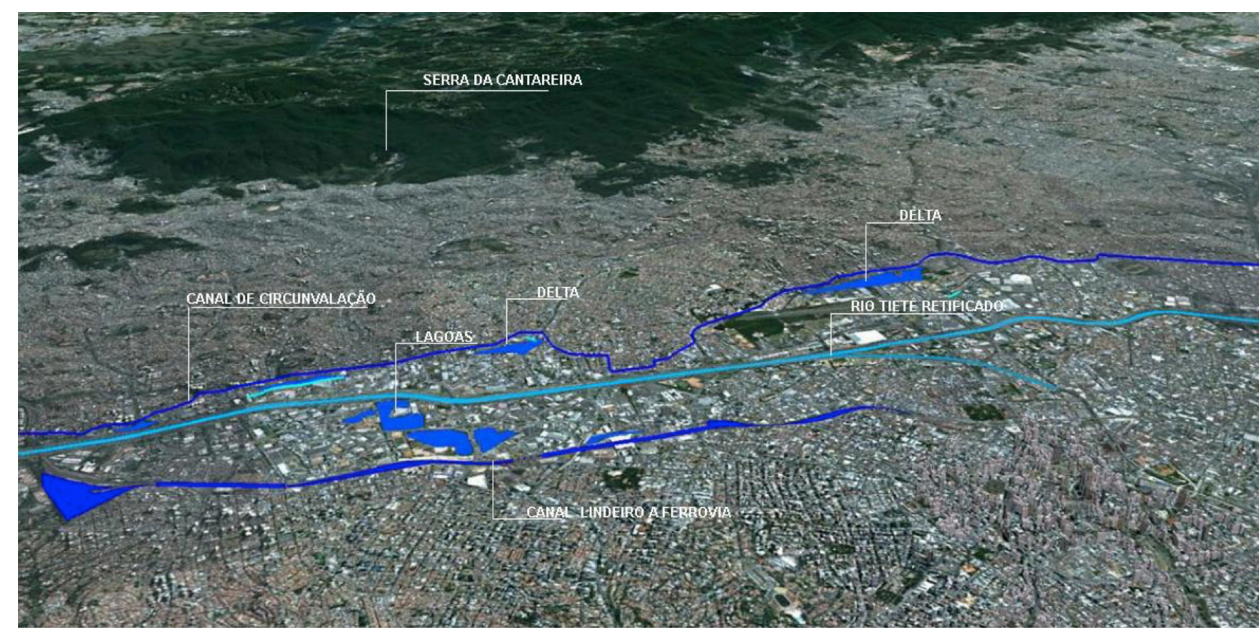


Figura 5: Arco Tietê: Carandirú: Canal Local (duplo) Av. Zaki Narchi com Reservatório de Retenção e Área Verde Alagável. Fonte: Elaborado a partir de Imagem de Satélite Google Earth, 2013.
Os Deltas artificiais, que se localizam entre o canal de circunvalação e o Tietê, são como grandes lagoas, uniões de rios e córregos com grande presença na paisagem que, ampliam as áreas de retenção nesta região. Estão em áreas estratégicas: do ponto de vista hídrico, porque articulam sempre a junção de rios e córregos, e urbanístico porque conferem per se, qualidade aprazível, por seu desenho, àquele entorno tão esgarçado.

Estes deltas são auxiliares do canal de circunvalação e podem ser implementados em concomitância ou em tempos diferentes, sem que ocorram conflitos.

Os Canais Locais se configuram em menores proporções e à jusante dos deltas, ou seja, são intervenções mais próximas ao rio Tietê. São canais transversais aos afluentes, com medidas reduzidas e implantados lindeiros a algumas ruas acompanhando o percurso dos pedestres. Funcionam também como canais de filtragem e, dada sua escala manejável e à ausência de desapropriação, poderão ser executados em casos mais numerosos, pulverizados.

Foram elencados no projeto alguns dos principais contribuintes do Tietê para uma procura inicial destes leitos onde pequenos canais-piloto podem ser implantados: um primeiro, transversal ao Carandirú pela avenida Zachi Nachi (Figura 5), o segundo cruzando o Mandaqui pela rua Madalena de Madureira e um terceiro, que cruza e interliga os córregos Água de Pedra e Cabuçú de Baixo, estende-se desde a rua Balsa até a avenida Nossa Senhora do Ó.

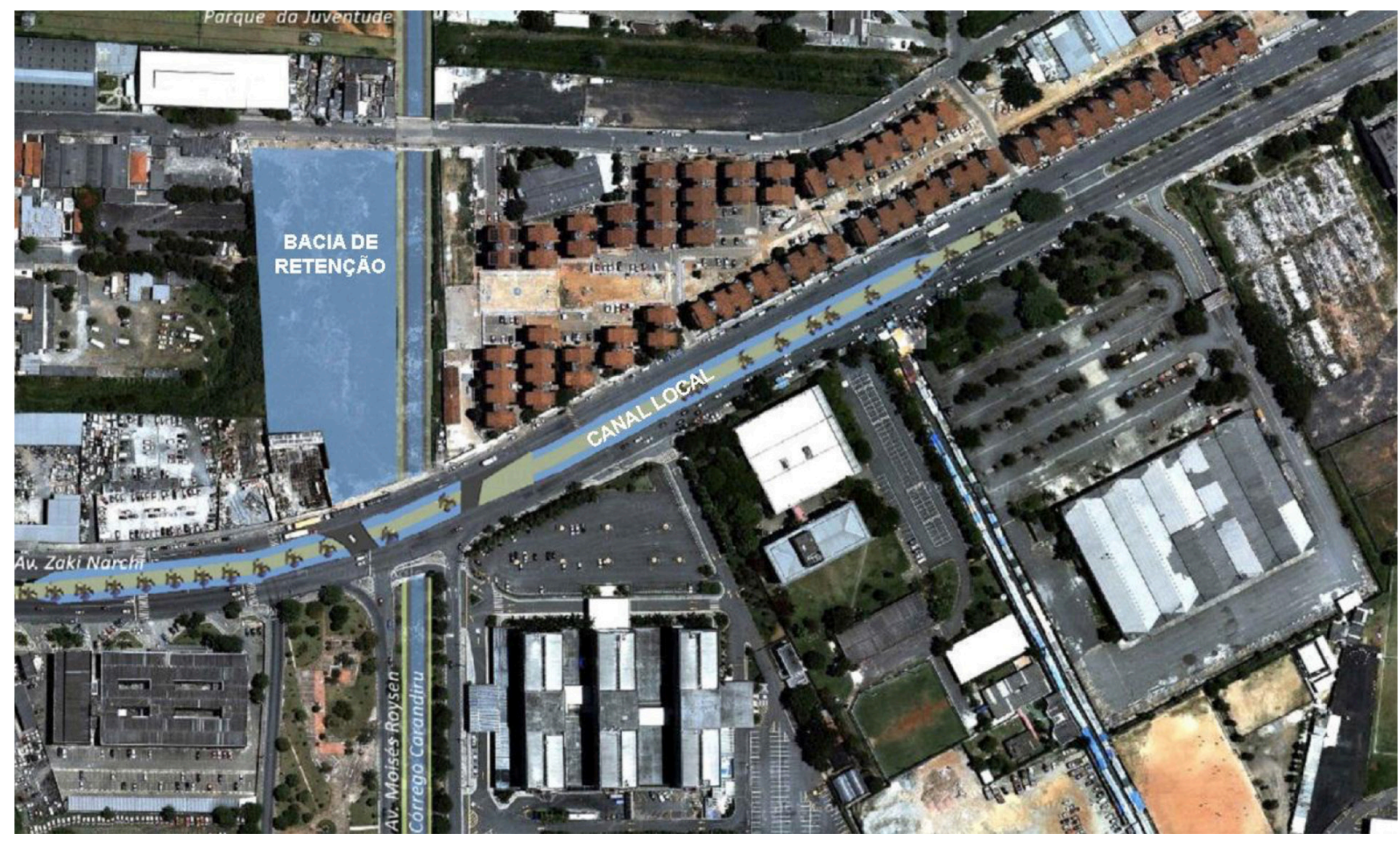


5 Projeto elaborado por ocasião do Prêmio Prestes Maia 2006. Uma cicatriz marca a cidade: soluções para o Elevado. Autores: Arquitetos: Autora do presente artigo (coordenação), Flávio Marcondes, Hector Vigliecca, Tito Lívio Frascino, Vera Santana Luz. Consultores Eng. Renato Zuccolo - Águas; Eng. Cláudio Macedo/Sistran - transportes; Agrimensor Irineu Idoeta - zoneamento/aerofotogrametria. Publicado Revista do Programa de Pós-Graduação em Arquitetura e Urbanismo da FAUUSP, São Paulo, v18, n² 29, p. 227-288, JUN/2011.

Figura 6: Perspectiva aérea da Ligação Leste-Oeste: imagem do viaduto Antártica: trens de passageiros, sistema viário de autos e ônibus, canal drenante e paisagístico, lagoas. Fonte: Foto Aérea de autoria da Equipe de Projeto de 2006, publicado na Revista do Programa de Pós-Graduação em Arquitetura e Urbanismo da FAUUSP, São Paulo, v18, n²29, p. 227-288, JUN/2011.

\section{Projeto 2 - Ligação Leste-Oeste de SP Prêmio Prestes Maia 2006. Uma cicatriz marca a cidade: soluções para o Elevado 5}

Lançado em 2006 pelo Governador José Serra como busca de soluções para a cicatriz urbana/minhocão em SP, no projeto para o Prêmio Prestes Maia, tínhamos como pressuposto o desmonte do Elevado. Ficava a pergunta de como escoar o fluxo da ligação Leste-Oeste da cidade.

A ideia do projeto é a de uma dupla reposição, da história e da geografia, associada à resolução e proposição dos fluxos da ligação leste-oeste consequente ao desmonte do elevado. A proposta supõe tal ligação pelos trilhos da antiga Sorocabana/Central do Brasil/Santos - Jundiaí que sempre correram no mesmo leito, donde sua grande largura, aproximadamente $100 \mathrm{~m}$, que comportava principalmente o fluxo de carga. Nesta faixa estão também o canal lindeiro proposto, articulado a um sistema de lagos na área da Água Branca e nos pátios Rudge e Lapa - agora obsoletos - da ferrovia (Figura 6).

O leito ferroviário subutilizado, incorporava ainda, além da intensificação dos trens de passageiros e o consequente translado da carga para o ferro anel, um sistema viário binário (Figura 7).

\section{O canal e os lagos}

O canal e os lagos se articulam com córregos destampados sempre que possível. O conjunto funcionaria como reserva-dreno das águas que vêm do espigão além de umidificar o ar. A ideia é que este canal freie a velocidade das águas, como um canal

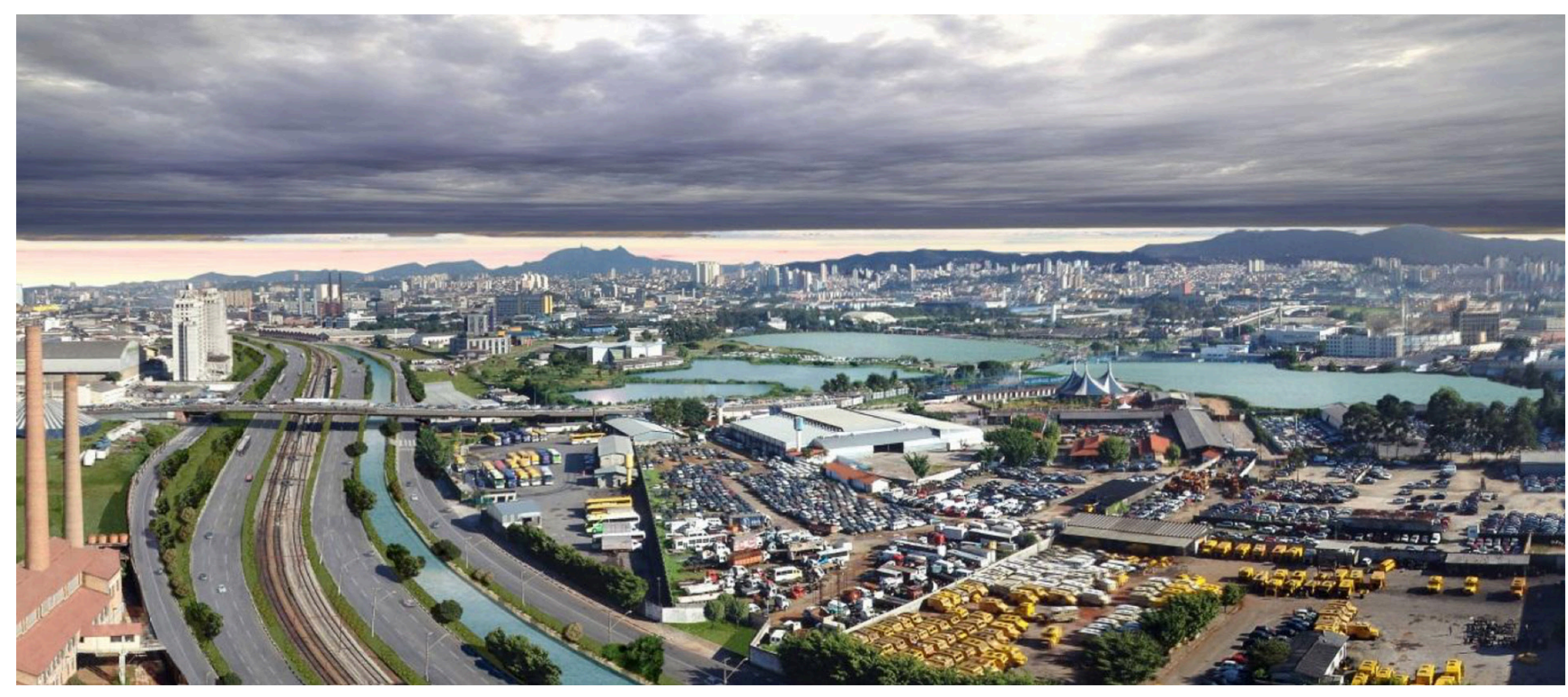




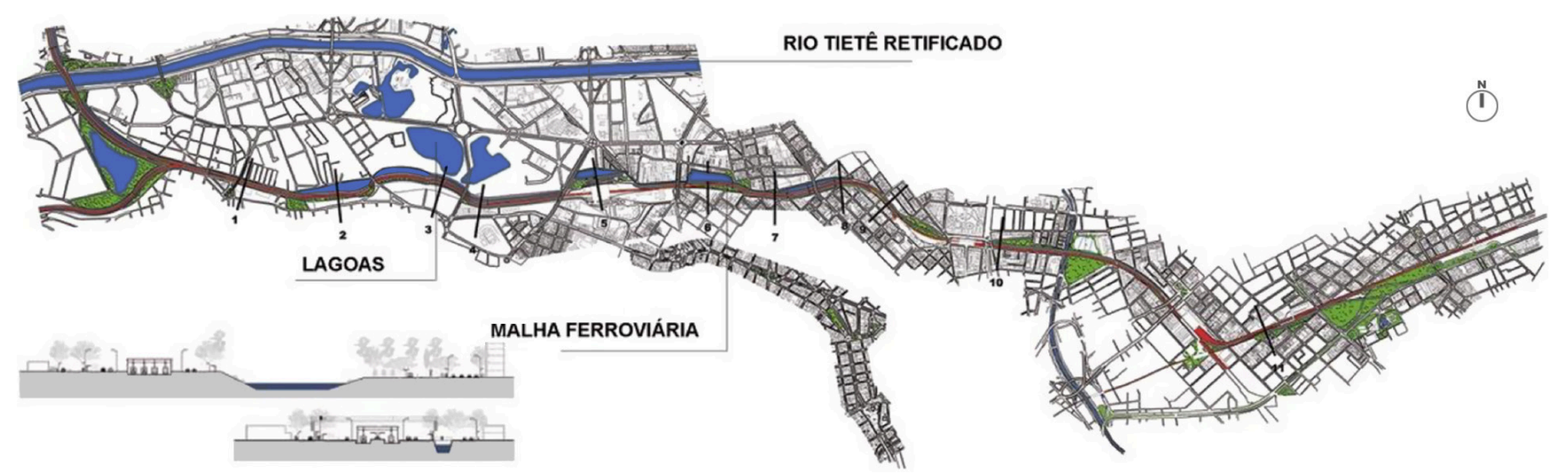

Figura 7: Levantamento cadastral de São Paulo com o projeto da Ligação Leste-Oeste de Bresser à Lapa: Trilhos, Canal, Lagoas. Abaixo: Cortes: Trilhos/ Canal/ Lagoas. Fonte: Elaborado com base no Acervo Técnico do Gegran (Grupo Executivo da Grande São Paulo) e Sobreposição do Mapa Hidrográfico de São Paulo, Tietê/ Afluentes e Sara Brasil 1930: Leito Maior, 2013.

6 Relatório Técnico do Eng. Renato Zuccolo para o Memorial Descritivo: Contribuição ao controle de inundações - Abrangência - Os corpos d'água criados, canal e lagos, constituem dispositivos que possibilitam que os afluentes abrangidos tenham suas descargas máximas no Rio Tietê dentro dos limites fixados pelo projeto implantado neste rio. Tais limites são as chamadas "vazões de restrição de descarga" nesse rio, fixadas pelo "Plano de Macrodrenagem da Bacia Hidrográfica do Alto Tietê", sem as quais o Município de São Paulo continuará sujeito à consequência de inundações. Diretrizes construtivas do canal (e lagos) - Claro que nesta fase, pode-se apenas conceituar alguns dos principais dispositivos do que o sistema deverá dispor. Em projeto, oportunamente, as complexas relações do canal com todas as utilidades urbanas serão resolvidas. Em especial, as interseções com as faixas transversais viárias (como, por exemplo, os cruzamentos com projeções de avenida Pacaembu,

... continua na página 10 ... parador, reservando-as nos lagos e finalmente, lentamente deságue-os no Tietê. A península resultante inicia-se na foz do Tamanduateí, estende-se até a Lapa e é ladeada pelo rio Tietê. Esta península poderá tornar-se uma área de excelência urbana não só pela diversidade de usos e grande oferta infra estrutural, mas também pela nova paisagem criada pelas águas. 6

\section{O entorno}

Dado que o projeto pretende otimizar a capacidade de infraestrutura ferroviária, viária e hídrica, ação que irradiará em seu entorno, prevê-se que serão necessárias sucessivas operações urbanas na área de influência imediata do projeto. Tal ação acarreta a necessidade de revisão das leis urbanísticas para proposições de novos coeficientes de aproveitamento, porém mantendo rígido controle sobre a taxa de ocupação e as devidas regulamentações quanto à permeabilidade do solo, em se tratando de um território de várzeas. Novos usos deverão ocorrer com a atualização da legislação: em zonas onde indústrias foram desativadas, prevendo mesclar os vários usos (residência, serviços e comércio e usos institucionais) assim como nas regiões ao redor das estações que tendem a adensar-se.

\section{Projeto 3 - Projeto para o Córrego Guaraú/Cabuçú de Baixo - Concurso Renova SP, 20107}

Entendendo que o problema das águas urbanas envolve todo o sistema de bacias e sub-bacias, este projeto faz referência aos tão importantes tratamentos e retenções de águas à montante, para as regiões de cabeceiras, em conjunto com o planejamento integrado (controle de cheias) ou seja, parques lineares, habitação e transportes de cada município.

A proposição envolve retenções articuladas em sistemas de barragens adjacentes à maior estação de tratamento da Sabesp. Sua localização no limite entre área não aedificandi da Serra da Cantareira e o início da área urbanizada da metrópole possui altas declividades e erosão. 


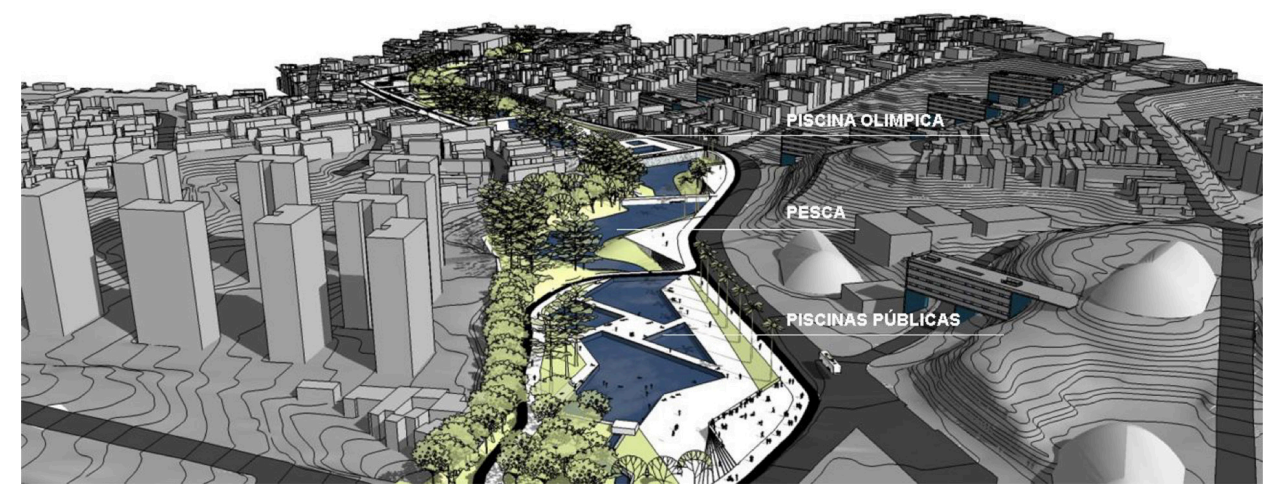

Figura 8 (em cima): Proposta para o Concurso Público Renova São Paulo: córrego Guaraú e Sistema de Piscinas Públicas, que desaguam no córrego Cabuçú de Baixo e consequentemente no rio Tietê, 2010. Fonte: Imagem desenvolvida pela equipe de projeto, 2010.

Figura 9 (meio): Proposta para Concurso Público Renova São Paulo: córrego Guaraú e Sistema de Piscinas Públicas, que desaguam no córrego Cabuçú de Baixo e consequentemente no rio Tietê. 2010. Fonte: Imagem desenvolvida pela equipe de projeto, 2010.

Figura 10 (embaixo): Proposta para Concurso Público Renova São Paulo: córrego Guaraú e Sistema de Piscinas Públicas, que desaguam no córrego Cabuçú de Baixo e consequentemente no rio Tietê. 2010. Fonte: Imagem desenvolvida pela equipe de projeto, 2010.
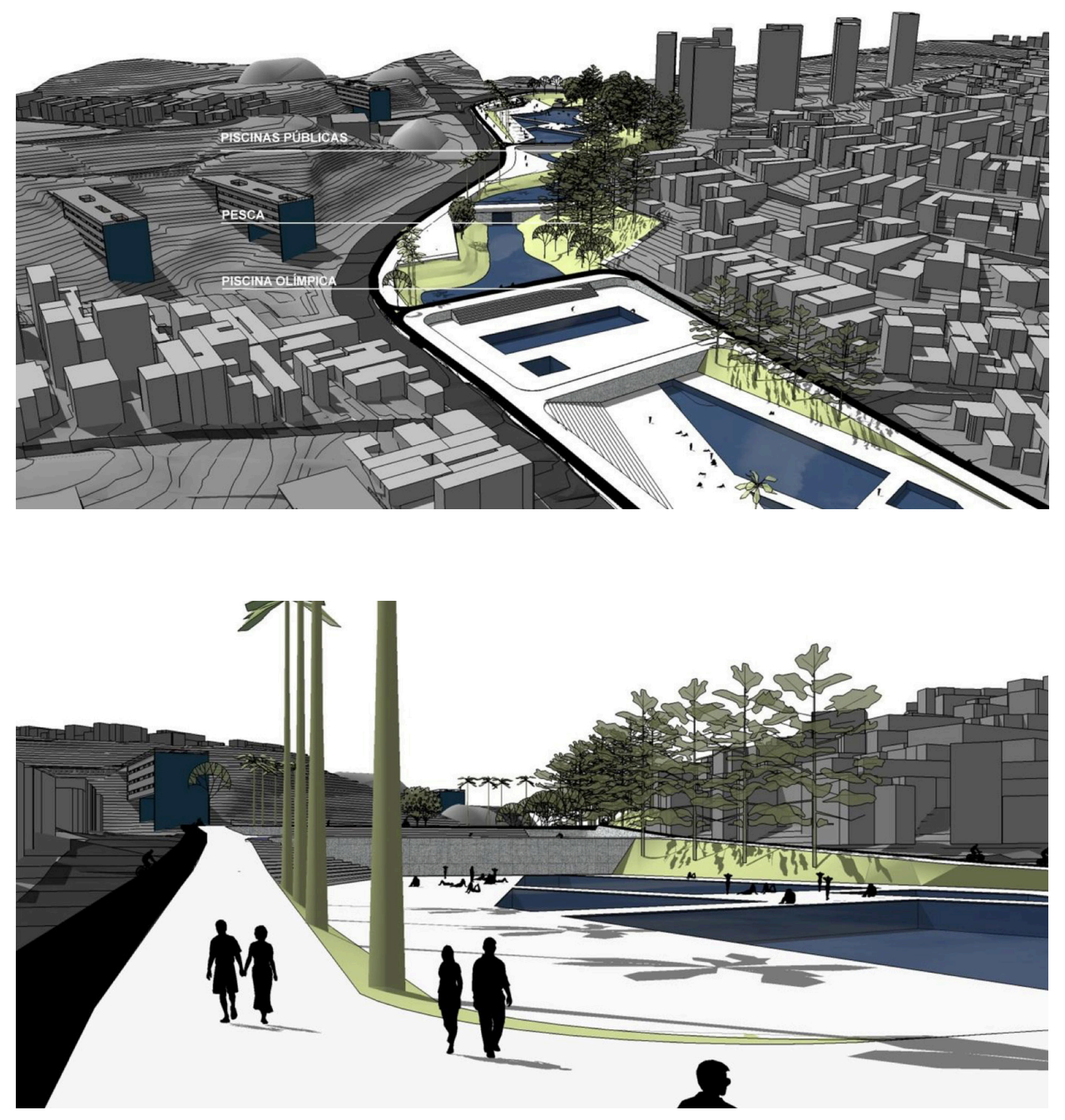
... continuação da nota 6 ... prolongamento da avenida Pompéia e viaduto Antártica) com suas presentes canalizações (dos afluentes, etc.), deverão ser harmonizadas. Em relação a entrada das águas no canal, ocorrerá uma multiplicidade de situações, e, quanto às saídas d'água do canal, haverá um número dessas bem próximo ao número de afluentes abrangidos. Em outras palavras, os caminhos plúvio-fluviais hoje existentes entre a ferrovia e o Rio Tietê, provavelmente serão mantidos em número, naturalmente disciplinando-se (melhorando-se) tais condutos, os quais serão, tanto quanto possível tornados abertos. Poderá ocorrer que, mesmo o canal em si, em tramos bem limitados, tenha que ser coberto. O canal (adicionado aos lagos) terá função permanente, com circulação de águas, desejavelmente apenas de origem pluvial superficial e freática (isto é, das nascentes). Também, o canal (e lagos) terá função de controle de inundações. A primeira função será viabilizada pela parte mais profunda do canal (e lagos) com saídas dimensionadas de tal forma que, seja escoado o caudal, no mesmo "ritmo" com que entrar. Quanto à segunda função esta será viabilizada pela porção superior do canal (e lagos) com saídas bem maiores que as da parte inferior, de forma que se escoe para jusante (em demanda ao Rio Tietê), em um período de tempo determinado, de sorte a não ser excedida a vazão que cada leito de afluente comportar, isto é, de forma que o "volume de espera" possa, sem problemas, ser esvaziado.

7 Projeto elaborado para o Concurso Renova São Paulo organizado pela Secretaria da Habitação - SEHAB, SP. Autor: Autora do presente artigo. Colaboradores: Arquitetos Jorge Felix, Renato Sordi. Consultor Engenharia Hidráulica: Eng. Francisco José Toledo Pisa.
Considerando tal declividade, foi proposto um parque aquático ladeado por ciclovia e projetado a partir da sequência de 5 barragens. Neste sistema propôs-se a criação de um conjunto de reservatórios, piscinas e lagos, que visa, de um lado, auxiliar a montante o rio Tietê e ao mesmo tempo proporciona extensa área de lazer. Articula-se assim, os dois lados urbanos do córrego, associando-os aos parques adjacentes da Cantareira e Horto Florestal.

A pergunta correlata nestas escalas e sobretudo em São Paulo é sobre como a cidade se estrutura, esta vastidão com profusão hídrica e topografia acidentada em extensão de $1.500 \mathrm{~km}^{2}$, diversamente das planas Paris com $105 \mathrm{~km}^{2}$ e Manhattan com $127 \mathrm{~km}^{2}$. São os mesmos $\sim 80 \mathrm{~km}$ de rede de metrô em SP vis a vis $\sim 200 \mathrm{~km}$ em Paris e $\sim 400 \mathrm{~km}$ em NY. A mancha infra estrutural em equivalência à mancha urbana, novamente dá a medida e a amplitude do contrato social correspondente a cada sociedade. Do ponto de vista do desenho da cidade e de sua habitabilidade e fruição, se a geografia se configura como vetor nas grandes escalas, no caso das áreas em questão, dada sua grande extensão e congestão, parecia invisível.

Reiterando, afinal, se a razão instrumental, em princípio civilizatória, passa a ter em si própria o seu sentido - e agir, portanto, independente da cultura - fica sem sentido. Parece ser o que tem ocorrido entre nós. Correlacionada à ideia de vida ativa de Hannah Arendt e à ação da sociedade civil no seu melhor, a ideia da ação da arquitetura seria tornar a cidade visível e táctil, apreendendo-a ética, técnica e esteticamente em todas as suas escalas.

\section{Considerações Finais}

O nexo entre os três projetos, além de ligados à infra estrutura é de uma proposição estética da paisagem.

A arte e a arquitetura nos põe, às vezes, questões que normalmente não percebemos sem o estopim de sua ação e existência. Nos projetos apresentados há uma certa apreensão em relação à cada paisagem que envolve um olhar em situação: como tornar visível tal situação-paisagem imersa num excesso de juxtaposições? das extensões territoriais que as abarcam associadas aos passos e descompassos de suas alterações no tempo. Propõe-se uma articulação entre o desenho da geografia e da infra estrutura numa vontade de nova evidência e desenho da paisagem.

A sobreposição do Levantamento SARA Brasil (a natureza primeira das várzeas) em relação ao mapa cadastral atual de São Paulo com seus rios e córregos retificados e canalizados, levaram a um terceiro desenho, uma terceira situação-paisagem criada esteticamente: este o elo, ou fio condutor dos três projetos.

No $1^{\circ}$, da ligação leste-oeste, o canal lindeiro aos trilhos e às grandes lagoas de retenção criam um novo desenho ligado a uma antiga latência (o rio meândrico) e consequentemente uma nova situação-paisagem. No $2^{\circ}$ projeto, para o Arco-Tietê a nova situação - radical em certa medida porque emblemática e eminentemente conceitual - dá-se em 3 cotas distintas e próximas: na mais alta (no sopé da Cantareira $\sim 730)$ o grande canal de circunvalação, na seguinte $(\sim 725)$ os deltas que recebem córregos tornados lagoas e na cota mais próxima ao Tietê, ( 720) pelos canais locais; 
sempre no cotidiano do cidadão. No $3^{\circ}$ projeto, as piscinas públicas - em topografia de grande declive - são niveladas pelas 5 pequenas barragens, aí também numa topografia criada, ampliando vastamente o fio d'água do Córrego do Guaraú. As piscinas (espelhos d'água sobre reservatórios ocos destinados a retenções) alternam-se com lagos, aparentemente naturais, e ligam os dois lados daquele entorno esgarçado e originalmente seccionado pelo córrego; e o desenho oblíquo das piscinas traça as direções de contato.

\section{Referências bibliográficas}

ARENDT, Hannah. A Condição Humana. $11^{\circ}$ ed.; Rio de Janeiro: Forense Universitária, 1997.

MERLEAU-PONTY, Maurice. O Olho e o Espírito. In: Textos Selecionados. Col. Pensadores. $2^{a}$ ed. São Paulo: Abril Cultural, 1984.

REIS GOULART, Nestor. São Paulo-Vila Cidade Metrópole. São Paulo: Via das Artes, 2004.

SUMNER, Anne Marie. Arquitetura e Infraestrutura: um percurso de projeto. Tese (Doutorado em Arquitetura e Infraestrutura) - Faculdade de Arquitetura e Urbanismo da USP. Universidade de São Paulo, São Paulo, p. 136. 2002.

SUMNER, Anne Marie. Opacidade e situação. Óculum 4 - Revista Universitária de Arquitetura, Urbanismo e Cultura - FAUPUCAMP, Campinas, p.38-44, nov./1993.

SUMNER, Anne Marie. Ideia de construção de um escritório experimental de projetos. Revista do Programa de Pós-Graduação em Arquitetura e Urbanismo da FAUUSP, São Paulo, v. $18, n^{\circ} 29$, p. 227-288, jun./2011. 